\title{
Allergic Rhinitis and Rhinopharyngitis - How Often We Meet them in the Occupational Pathology?
}

\author{
Dermendzhiev $\mathbf{S}^{1,2}$ and Ilkova $\mathbf{P}^{2}$ \\ ${ }^{1}$ Division of Occupational Diseases and Toxicology, 2nd Department of Internal Medicine, Faculty of Medicine, Medical University \\ of Plovdiv, Bulgaria
}

2Department of Occupational Diseases and Clinical Allergy Activity, University Multiprofile Hospital for Active Treatment, "St. Georgi", Plovdiv, Bulgaria

*Corresponding author: Ilkova P, Department of Occupational Diseases and Clinical Allergy Activity, University Multiportfolio Hospital for Active Treatment, "St. Georgi", Plovdiv, Bulgaria

\section{ARTICLE INFO \\ Received: 幽 September 10, 2020 \\ Published: 幽 September 23, 2020 \\ Citation: Dermendzhiev S, Ilkova P. Allergic Rhinitis and Rhinopharyngitis - How Often We Meet them in the Occupational Pathology?. Biomed J Sci \& Tech Res 30(4)- 2020. BJSTR. MS.ID.004986.}

Keywords: Allergic Rhinitis; Occupational Etiology; Detection of Occupational Diseases

\section{ABSTRACT}

The World Allergy Organization suggests that 400 million people suffer from allergic rhinitis, which is the most common of all, and 300 million-number asthma is estimated to reach 400 million by 2025 and rapidly increasing in children.Work-related rhinitis may be distinguished into:

(1) Occupational rhinitis that is due to causes and conditions attributable to a particular work environment.

(2) Work-exacerbated rhinitis that is pre-existing or concurrent rhinitis exacerbated by workplace exposures.

Since it causes little disability, it is often neglected by affected individuals. However, it is often the preliminary manifestation of a respiratory disorder that could lead to physical complications and socio-economic disability.

Nevertheless, raising public awareness to work-related pathology during lastyears, the level of detection of occupational diseases in Bulgaria is significantly lower in comparison to EU member countries. Here we present a summarized report on results ofactivities, according to the contract with "Labor conditions" Fund of Ministry of Labor and Social Policy,conductedintheDepartment of Occupational Diseases and Clinical Allergy Activity, University Multiprofile Hospital for Active Treatment, "St Georgi" Plovdiv,Bulgaria.

\section{Summary}

Report on results of diagnostic and treatment activities, according to the contract with "Labor conditions" Fund of Ministry of Labor and Social Policy,conductedintheDepartment of Occupational Diseases and Clinical Allergy Activity, University Multiprofile Hospital for Active Treatment, "St Georgi" Plovdiv, Bulgaria

\section{Introduction}

The World Allergy Organization suggests that 400 million people suffer from allergic rhinitis, which is the most common of all, and 300 million-number asthma is estimated to reach 400 million by 2025 and rapidly increasing in children[1]. The professional rhinitis is an episodic demonstration with symptoms likesneezes, rhinorrhea and nasal obstruction correlated in the activity of the work.Work-related rhinitis may be distinguished into:
(1) Occupational rhinitis that is due to causes and conditions attributable to a particular work environment.

(2) Work-exacerbated rhinitis that is pre-existing or concurrent rhinitis exacerbated by workplace exposures[2].

Since it causes little disability, it is often neglected by affected individuals. However, it is often the preliminary manifestation of 
a respiratory disorder that could lead to physical complications and socio-economic disability[3]. Nevertheless, raising public awareness to work-related pathology during last years, the level of detection of occupational diseases in Bulgaria is significantly lower in comparison to EU member countries[4].Allergic rhinitis is not only considered as a disease entity but also in the context of medical certification as the allergic disease associated with occupational exposure. The interval enters the first exposure to the aggressive agent and the development of the symptoms can vary of a few weeks in more than twenty years, with a variable period of latency between one and three years. The diagnosis of professional rhinitis depends on medical anamneses and on a survey on the employment [3].

According to a research OSHA (Occupational Safety and Health Administration): $22 \%$ of the European workers are in touch with dangerous substances during at least a quarter of their working time[5]. The newest studies show that there isenough convincing evidence that tight relationships between the upper and lower airways also apply to the workplace context. Most patients with occupational asthma (OA) also suffer from occupational rhinitis (OR), although OR is 2 to 3 times more common than OA[6]. According to the statement of EAACI, the group of Occupational rhinitis includes Allergic OR and Non-allergic OR.Allergic OR encompasses both IgE-mediated OR and non-IgE-mediated OR depending on the molecular weight of the agent and also the role ofIgE-mediated mechanism, respectively. Non-allergic OR - This category encompasses different types of rhinitis caused by the work environment through irritant, non-immunological mechanisms.

\section{Material and Methods}

Detailed overview and analysis on all the Reports about results of the diagnostic and health care activities for the period 20172019, based on the of contractbetween "Labor Conditions" Fund and University Multiprofile Hospital for Active Treatment, "St Georgi" Plovdiv have been conducted. The expert assessment regarding the occupational etiology of patients diagnosed with allergic rhinitis was performed onthe basis of the current regulations on the administration of occupational pathology in Bulgaria[7]. In all patients with allergic rhinitis and suspected work related origin were conducted skin-allergy Prick tests with standard indoor and outdoor allergens panel as well as Epicutaneous test with European standard series for epicutaneous testing (European Environmental and Contact Dermatitis Research Group).The full list of allergens are presented in Table 1.The following diagnostic procedures were performed in all patients - detailed inquiry of inhaled agents in the work environment, general and occupational anamnesis, full ORL status, skull $\mathrm{x}$ ray in in semi-axial projection, consultation with other specialist - pulmonologist, allergy, blood testing anddiscussion in front of the specialized commission including specialist in occupational pathology (Table 1).
Table 1: List of Allergens.

\begin{tabular}{|c|c|}
\hline \multicolumn{2}{|c|}{ Prick test Indoor and Outdoor Allergens - Checked on 20 min } \\
\hline Grass & Mites \\
\hline 688 (5 grasses) & 314 (D. farinae) \\
\hline 687 (4 cereals) & 315 (D. pteronissimus) \\
\hline Trees & Animal allergens \\
\hline 696 (Beech) & 507 (Cat) \\
\hline 702 (Birch) & 509 (Dog) \\
\hline 701 (Willow) & 506 (Fluff and feather) \\
\hline Weed & Control \\
\hline 604 (Ambrosia) & Positive control (histamine) \\
\hline 605 (Common wormwood) & Negative control \\
\hline 665 (Plantain) & \\
\hline 714 (Chenopodiaceae) & \\
\hline
\end{tabular}

EpicutaneousTest with European Standard Series for Epicutaneous Testing

\begin{tabular}{|c|c|}
\hline Potassium dichromate & $\begin{array}{l}\text { 4-tert-Butylphenolformaldehyde } \\
\text { resin }\end{array}$ \\
\hline 4-phenylenediamine base (PPD) & 2-Mercaptobenzothiazole (MBT) \\
\hline Thiuram mix & Formaldehyde \\
\hline Neomycin sulfate & Fragrance mix I \\
\hline Cobalt (II) chloride hexahydrate & Sesquiterpene lactone mix \\
\hline Benzocaine & Qua ternium 15 \\
\hline Nickelsulfate heexahudrate & $\begin{array}{l}\text { 2-methoxy-6-n-pentyl-4- } \\
\text { benzoquinone (Primin) }\end{array}$ \\
\hline Clioquinol & $\begin{array}{l}\text { 5-chloro-2-methyl-4-isothiazolin- } \\
\text { 3-one (Kathon CG) }\end{array}$ \\
\hline Colophony & Budesonide \\
\hline Paraben mix & Tixocortol-21-pivalate \\
\hline $\begin{array}{l}\text { N-lsopropyl-N-phenyl-3- } \\
\text { phenylenediamine (IPPD) }\end{array}$ & Methyldibromoglutaronitrile \\
\hline Lanolin Alcohol & Fragrance mix \| \\
\hline Mercapto mix & Lyral (alfa-hexyl cinnamal) \\
\hline Epoxy resin & Composite obturation with evicrol \\
\hline Balsam Peru & $\begin{array}{l}\text { Material from crown containing } \\
\text { acrylamide }\end{array}$ \\
\hline
\end{tabular}

\section{Results}

Department of Occupational Diseases and Clinical Allergy Activity, University Multiprofile Hospital for Active Treatment, "St Georgi" Plovdiv, performs annual diagnostic and treatment activities under a contractbetween the hospital and the "Labor Conditions" Fund at the Ministry of Labour and Social Policy, Bulgaria. The Department is certified for diagnosis, treatment and expert assessment of patients with occupational diseases and clinical allergy by the Ministry of Health. For the period 2017 -2019, under the inpatient programs, 487 patients have been observed and in almost half of them, the professional origin of the diagnosed diseases was suspected or confirmed [8] (Figure 1). 


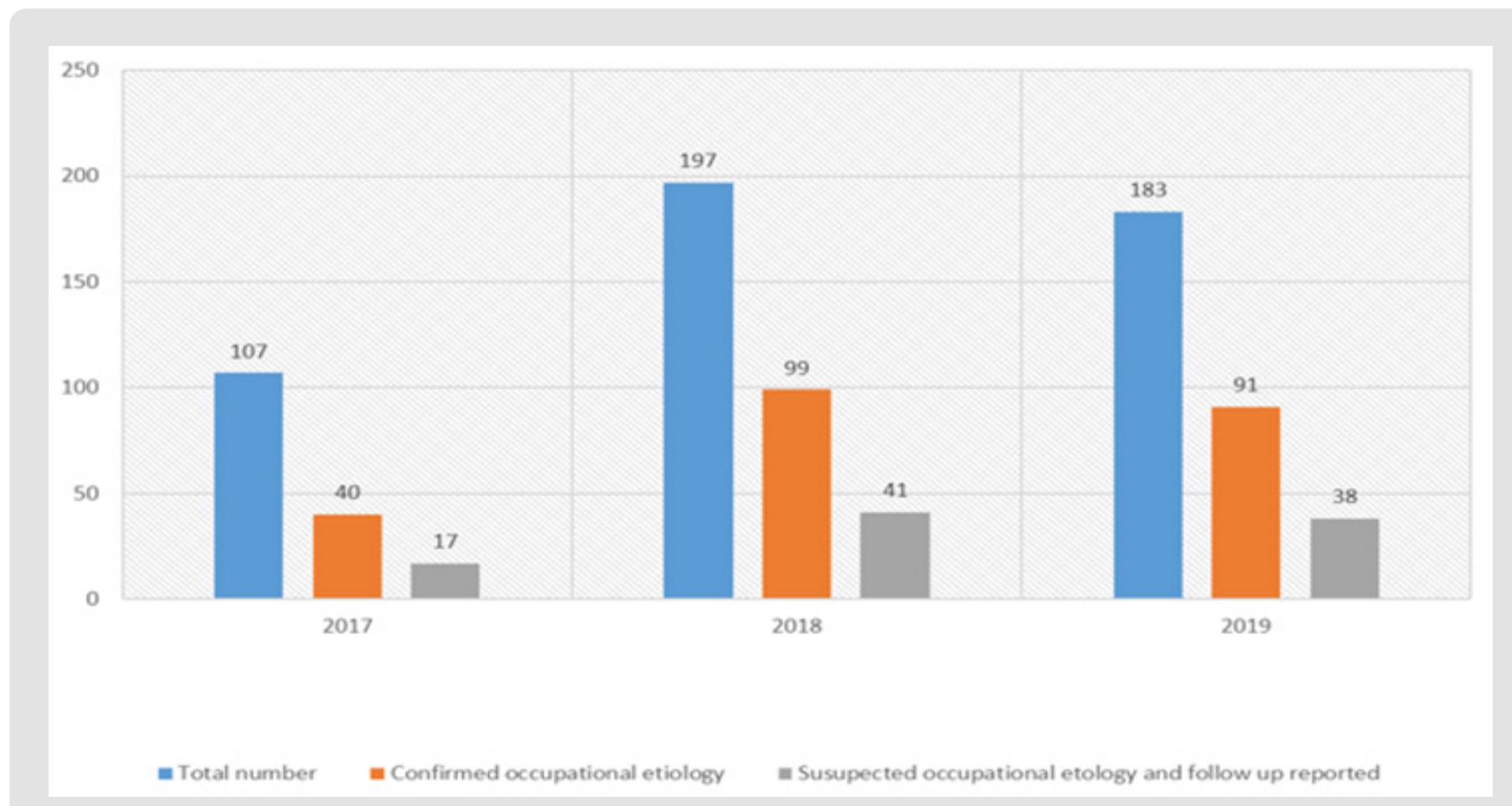

Figure 1: Total number of patients treated in Department of Occupational diseases and Clinical allergy activity, Multiprofile Hospital “St. Georgi”, Plovdiv for 2017-2019.

Occupational respiratory diseases were diagnosed in almost half of all patients have been observed. As can be seen from the attached chart, occupational rhinitis is more common than occupational asthma (Figure 2). A total of 80 patients with allergic rhinitis were diagnosed over a three-year period. According to the etiological reasons, the following results were reported(Figure 3).

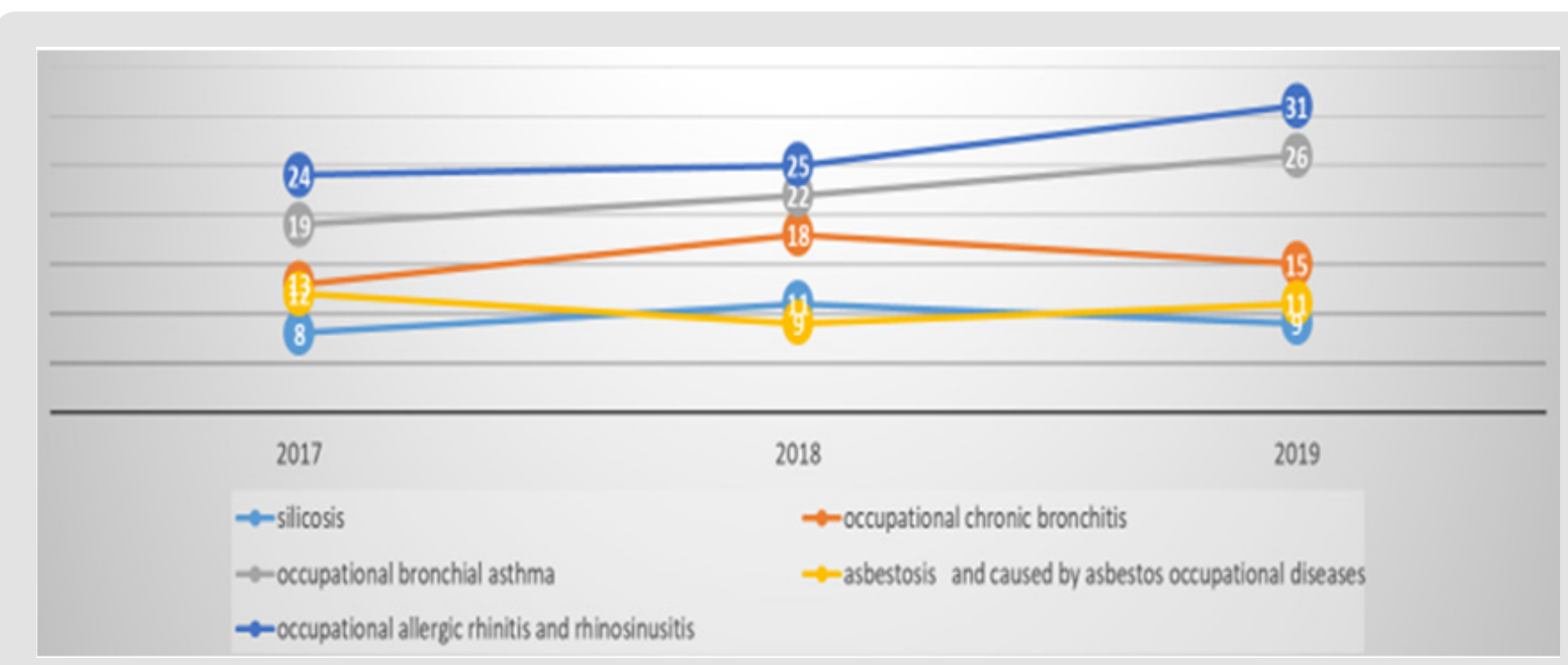

Figure 2: Number of patients with occupational diseases of respiratory system split by diagnosis 2017-2019. 


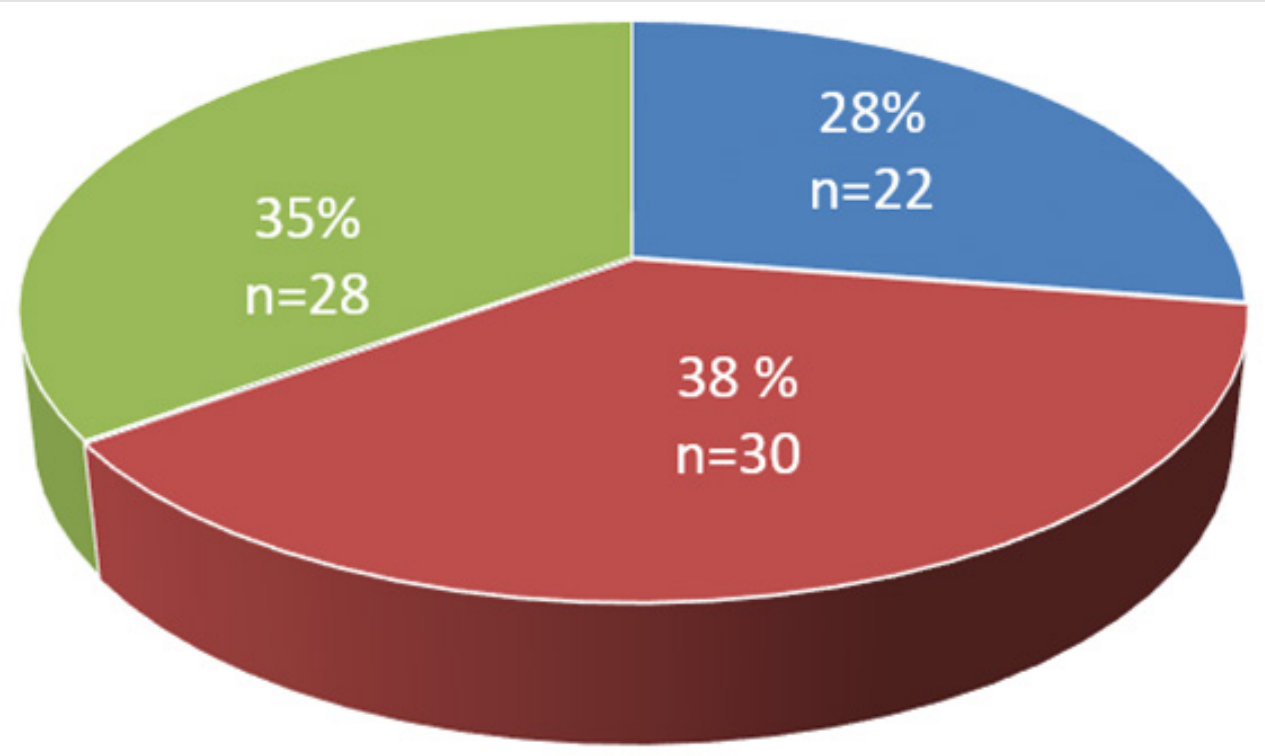

- allergic rhinitis of mixed etiology including occupational origin

- allergic rhinitis due to sensitization to micro-ticks, wood and grass pollen - vasomotor and drug-induced allergic rhinitis

Figure 3: Patients with confirmed allergic rhinitis and rhinopharyngitis split by etiology.

a) In 38\% of the patients hypersensitization to micro-ticks, wood and grass pollen were defined as a reason for allergic rhinitis

b) 28 patientswere diagnosed with vasomotor and druginduced allergic rhinitis

c) Occupational etiology were confirmed in $28 \%$ of patient.

\section{Conclusion}

(1) As the results of the deep analysis of all reports, we concluded that the share of allergic rhinitis is increasing in the respiratory pathology among occupational exposure patients.

(2) Number of patients with occupational origin of the rhinitis also growing.

(3) During the prosses of expert assessment of the patients with occupational rhinitis a lot of factors should be considered factors outside the work environment related to other common illnesses andmedications prescribed for them, the individual reactivity and characteristics of each patient shouldbealso taken into consideration.

\section{References}

1. Silvia M, Alejandro M (2016) Occupational Rhinitis. J Otolaryngol ENT Res 4(5): 00117.

2. Mosanto G, Vandenplas O, Van Wiik R G, Malo J L, Perfetti L, et al. (2009) EAACI position paper on occupational rhinitis, Respiratory Research 10: 16.

3. Maci L, Tavolaro M (2017) Occupational Rhinitis. J stem cell Bio transplant 1(1): 9.

4. (2018) National Program for Safety and Health at Work 2018-2020, Adopted by Decision № 801 of the Council of Ministers of 22.12.2017 Sofia.

5. (2003) European Agency for Safety and Health at Work Hazardous Substance Management Magazine 2003.

6. Vandenplas O, Hox V, Bernstein D (2020) Occupational Rhinitis. The Journal of Allergy and Clinical Immunology: In Practice.

7. National Statistical Institute.

8. Reports-analysis of the results of the performed diagnostic and treatment activities for 2017 - 2019, in accordance with the implementation of a contract between the fund "working conditions" and UMHAT "St. George" EAD - Plovdiv. 
ISSN: 2574-1241

DOI: $10.26717 /$ BJSTR.2020.30.004986

Ilkova P. Biomed J Sci \& Tech Res

(C) (P) This work is licensed under Creative BY Commons Attribution 4.0 License

Submission Link: https://biomedres.us/submit-manuscript.php

$\begin{array}{ll}\text { BIOMEDICAL } & \text { Assets of Publishing with us } \\ \text { RESEARCHES } & \text { - Global archiving of articles } \\ \text { - Immediate, unrestricted online access } & \text { - Rigorous Peer Review Process } \\ & \text { - Authors Retain Copyrights } \\ \end{array}$

